\title{
Spotlight on eltrombopag in the treatment of children with chronic immune thrombocytopenia
}

This article was published in the following Dove Press journal:

Pediatric Health, Medicine and Therapeutics

8 June 2016

Number of times this article has been viewed

\section{Michele P Lambert ${ }^{1,2}$ \\ 'Division of Hematology, The Children's Hospital of Philadelphia, ${ }^{2}$ Department of Pediatrics, Perelman School of Medicine, University of Pennsylvania, Philadelphia, PA, USA}

\begin{abstract}
Pediatric data on the use of thrombopoietin receptor agonists are fairly limited. The recent approval of eltrombopag by the US Food and Drug Administration for children aged $\geq 1$ year, based on data from two randomized, placebo-controlled clinical trials, may lead to the increased use of this drug in clinical practice, and therefore, it is important to have a basic understanding of the biology, pharmacokinetics, safety, and efficacy of the medication.
\end{abstract}

Keywords: ITP, pediatrics, treatment, thrombopoietin receptor agonists

\section{Introduction}

Immune thrombocytopenia (ITP) is an autoimmune disease resulting in an isolated low platelet count $\left(<100 \times 10^{9} / \mathrm{L}\right)$ due to a variable combination of immune-mediated destruction of platelets by various mechanisms, ${ }^{1,2}$ impaired platelet production, ${ }^{3}$ and inappropriate thrombopoietin (TPO) response. ${ }^{4}$ ITP is defined as "newly diagnosed", "persistent", and "chronic" if it is diagnosed within the first 3 months, between 3 months and 12 months, and after $>12$ months, respectively. ${ }^{5}$ ITP occurs in 1.9-6.4 in 100,000 children, ${ }^{6}$ and it is generally found in a child who is otherwise well often presenting with the dramatic onset of bruising and petechiae and very low platelet count. The majority of these children, however, resolve spontaneously within a few weeks and do not require treatment. ${ }^{7}$ A few patients with significant hemorrhage may require therapies directed at raising the platelet count. Occasionally, patients with pediatric ITP require treatment with second-line therapies, which may include immunosuppressive therapies (such as rituximab, azathioprine, mercaptopurine, and sirolimus), splenectomy, or, more recently, TPO receptor agonists (RAs).

TPO was first identified in the year 1994 as the main regulator of platelet mass in the well state.$^{8,9}$ TPO production appears to be constitutive in the liver and cleared primarily by binding to the TPO receptor (c-mpl) on platelets. Therefore, the TPO level increases as the platelet count decreases. Initial work to create first-generation TPO-RAs focused on recombinant protein technology, but was halted after some patients developed antibodies that cross-reacted with native TPO resulting in severe thrombocytopenia. ${ }^{10}$ The second-generation TPO RAs have been developed to avoid any of these complications and specifically lack any sequence homology with endogenous TPO.

Two TPO RAs have been studied in pediatric patients: romiplostim and eltrombopag. Eltrombopag (SB497115, Promacta, Revolade; GlaxoSmithKline plc, London, UK) was approved by the US Food and Drug Administration (FDA) for use in adults with chronic ITP in 2008 and in pediatric patients $\geq 1$ year of age with chronic ITP
Correspondence: Michele P Lambert Division of Hematology, The Children's Hospital of Philadelphia, 3615 Civic Center Boulevard, ARC 316G, Philadelphia, PA 19104, USA

Tel +I 2I5 5904667

Email lambertm@email.chop.edu
Pediatric Health, Medicine and Therapeutics 2016:7 39-43

39

Dovepress

http://dx.doi.org/1 0.2147/PHMT.590688 (c) (7) (5) 2016 Lambert. This work is published and licensed by Dove Medical Press Limited. The full terms of this license are available at https://www.dovepress.com/terms.php
and incorporate the Creative Commons Attribution - Non Commercial (unported, v3.0) License (http://creativecommons.org/licenses/by-nc/3.0/). By accessing the work you

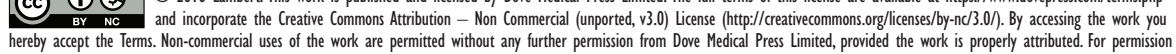
for commercial use of this work, please see paragraphs 4.2 and 5 of our Terms (https://www.dovepress.com/terms.php). 
who had had insufficient response to immunoglobulin, corticosteroids, or splenectomy, in August 2015. Eltrombopag, as the only TPO RA approved for use in pediatrics, is the focus of this review.

\section{Biology and dosing of eltrombopag}

Eltrombopag is a small molecule, non-peptide agonist that binds within the transmembrane domain of the TPO receptor resulting in signaling through the JAK/STAT and MAPK pathways similar to the signaling mechanism of TPO (Figure 1). ${ }^{11}$ It is a biphenyl hydrazone and is structurally distinct from endogenous TPO (Figure 2). Therefore, eltrombopag noncompetitively activates the TPO receptor by binding within the transmembrane domain to initiate the signaling cascade and cause both proliferation of megakaryocytes and differentiation resulting in generation of increased numbers of platelets. ${ }^{11}$ Eltrombopag is active only on human megakaryocytes. Because eltrombopag binds to a site distinct from endogenous TPO on c-mpl, the effects of eltrombopag in the presence of TPO signaling may be additive.

Eltrombopag is orally bioavailable and absorbed with peak absorption at 2-6 hours after administration. ${ }^{12,13}$ Food and polyvalent cations significantly decrease absorption (calcium, iron, magnesium), ${ }^{12,13}$ and therefore recommendations are that this medication should be taken on an empty stomach (at least 1 hour before or 2 hours after any meal) or at least 2 hours before or 4 hours after other medications, calcium-rich foods (dairy or calcium-fortified juices) or other supplements (particularly iron, selenium, zinc, and magnesium). The dietary restrictions can have a significant impact on patients' ability to take the medication. Hepatic impairment significantly increased plasma levels and prolonged half-life.

Eltrombopag is currently available in several dosing tablets: $12.5 \mathrm{mg}, 25 \mathrm{mg}, 50 \mathrm{mg}$, and $75 \mathrm{mg}$, and the maximum recommended daily dose is $75 \mathrm{mg}$. For children aged

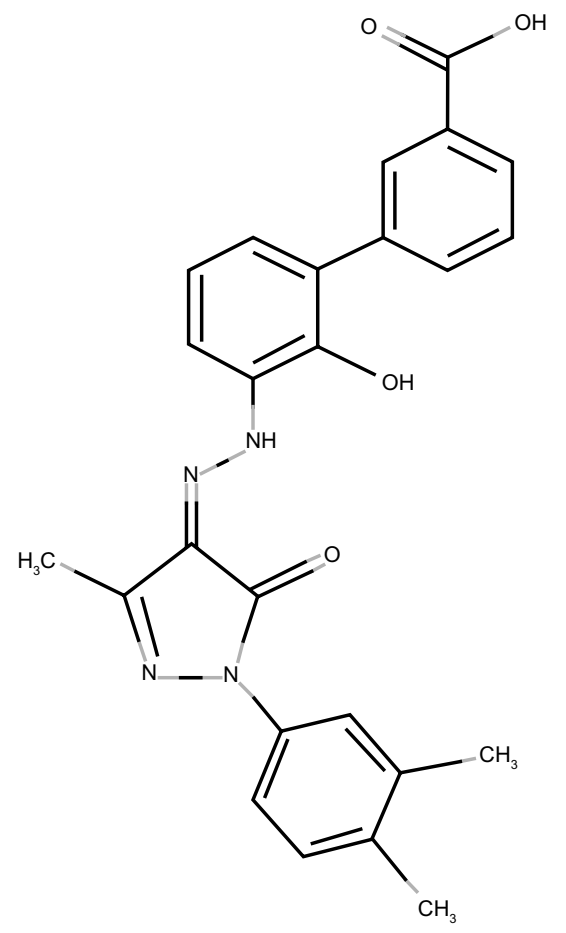

Figure 2 Chemical structure of eltrombopag.

$\geq 6$ years, the recommended starting dose is $50 \mathrm{mg}$ daily with dose adjustments made in $25 \mathrm{mg}$ increments, while the starting dose for children $1-5$ years is $25 \mathrm{mg}$. Monitoring of liver function tests and blood count are recommended during therapy as liver toxicity is a reported toxicity and dosing is based on platelet count parameters with the goal of therapy to maintain a platelet count between $50 \times 10^{9} / \mathrm{L}$ and $200 \times 10^{9} / \mathrm{L}$. Powder for oral suspension is in development for use in young children who cannot swallow tablets, but it has not yet become readily available outside of clinical trials. ${ }^{13}$ It is important to point out that all of the clinical trials were conducted with eltrombopag dosed per weight, while this dosing strategy does not take patient weight into account.

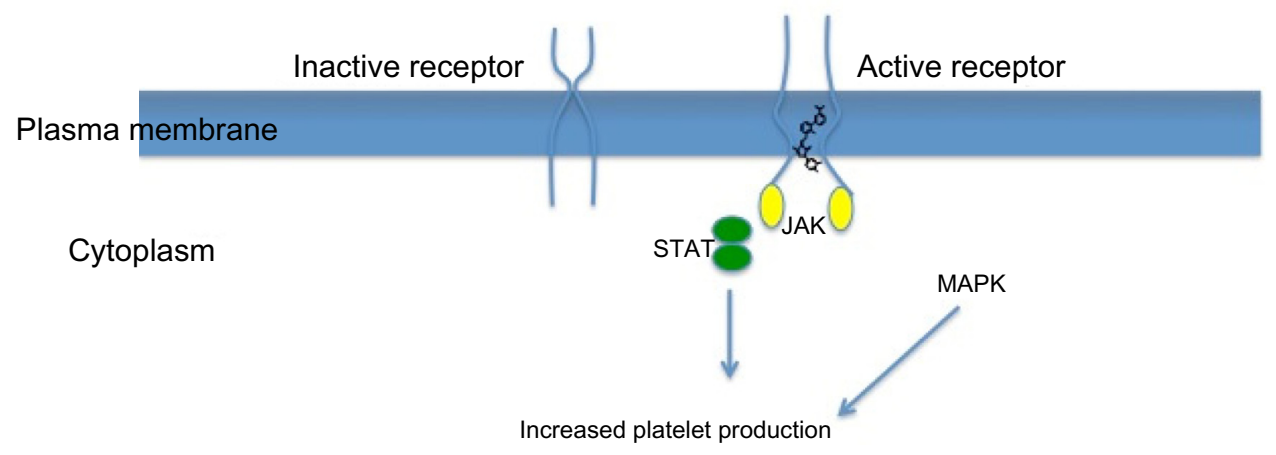

Figure I Simple schematic representing the location of TPO and eltrombopag binding and signaling through TPO receptor when ligands bind. Abbreviation: TPO, thrombopoietin. 
Therefore, clinicians may wish to consider patient weight when making starting dose decisions, particularly in very children or in children near the age where the recommended dose changes.

\section{Pediatric clinical trial results}

Two randomized, placebo-controlled, clinical trials have been performed in pediatric patients with ITP of $>6$-month duration using eltrombopag (because the definition of chronic ITP was changed from $>6$-month to $>12$-month duration between the time of the clinical trials design and completion, after the publication of new guidelines). The first study, called PETIT was a three-part, multicenter, international study performed at 22 centers across North America and the European Union. ${ }^{14}$ Children and adolescents aged 1-17 years were enrolled initially in an open-label dose-finding phase (15 patients). The next 67 patients were then assigned to a randomized, placebo-controlled study (2:1, eltrombopag:placebo). The second study, PETIT2, was a randomized, placebo-controlled study in children and adolescents aged 1-17 years. The primary end point in PETIT was to compare the percentage of patients who achieved a platelet count of $\geq 50 \times 10^{9} / \mathrm{L}$ at least once while on therapy ( $62 \%$ vs $32 \%$ placebo), while in PETIT2 it was to assess the ability of eltrombopag to produce sustained platelet count response (defined as platelet count of $\geq 50 \times 10^{9} / \mathrm{L}$ without rescue for $\geq 6$ weeks out of 8 weeks between weeks 5 and 12; 40\% vs 3\% for placebo). ${ }^{15}$ Both studies had an open-label portion as well, and during the open-label portion $\sim 80 \%$ of patients (54 [81\%] patients in PETIT and 70 [80\%] patients in PETIT2) had a platelet count of $\geq 50 \times 10^{9} / \mathrm{L}$ at least once. Clinical data also showed that eltrombopag was able to reduce bleeding symptoms (which do not always correlate with platelet count) in both PETIT (eltrombopag vs placebo: 14 [31\%] vs 18 [82\%]) and PETIT2 (23 [37\%] vs $16[55 \%])$.

\section{Other pediatric studies}

Several smaller studies have been published examining the use of eltrombopag in clinical practice outside of clinical trials. Most of these are case reports ${ }^{16,17}$; therefore, the data presented must be carefully interpreted. However, one study reports data from a larger cohort of patients treated at two larger medical centers treating patients with eltrombopag while not part of a clinical trial. Ramaswamy et al reported the use of TPO RAs in 33 patients. ${ }^{18}$ Of these, 12 children (mean age, 14.5 years; range, 3-19 years) received eltrombopag and $9 / 12$ achieved a platelet count of $\geq 50 \times 10^{9} / \mathrm{L}$ at least twice during the treatment duration and $57 \%$ had a platelet count of $\geq 50 \times 10^{9} / \mathrm{L}$ for $>50 \%$ of the time they were treated. One of these patients developed a thrombosis (provoked after an ankle fracture), but there were otherwise no serious adverse events (AEs).

Two randomized, placebo-controlled studies in pediatric patients have been published with the other TPO RA, romiplostim, which has not yet received FDA approval. ${ }^{19,20}$ These studies show that, like eltrombopag, treatment with romiplostim can result in increases in platelet count in children with chronic ITP. Bussel et al reported on a group of 22 children aged 12 months to $<18$ years with ITP of $\geq 6$-month duration who were randomized to romiplostim $(n=17)$ or placebo $(n=5)$ for 12 weeks. ${ }^{20}$ In this study, $88 \%$ of patients in the treatment group had a platelet count response (defined as a platelet count of $\geq 50 \times 10^{9} / \mathrm{L}$ for 2 consecutive weeks). There were no serious AEs in this study, and the AEs reported were mostly headaches and epistaxis. Interestingly, during the study, there was more bleeding related to AEs in the romiplostim-treated patients ( $71 \%$ vs $40 \%$ of patients), but the majority of these events were in the first 6 weeks of the study during dose titration in the treatment arm. ${ }^{20}$ The second study, published in the same year, is a singleinstitution, randomized, single-blind, placebo-controlled trial of romiplostim in 18 non-splenectomized pediatric patients aged 2.5-6 years with ITP of $>12$-month duration. In this study, the most common AEs in the romiplostim-treated patients were headache, epistaxis, cough, and vomiting (which all occurred less frequently than in the placebo group: $\%$ vs $16 \%$, respectively) and rash, which only occurred in the romiplostim group, and there were no serious AEs. The authors reported that $83.3 \%$ of patients maintained a platelet count of $>50 \times 10^{9} / \mathrm{L}$ for the study duration. ${ }^{19}$

\section{Side effects/monitoring Adverse reactions}

In the adult studies, the most commonly reported AEs were nausea, diarrhea, and upper respiratory infection. In pediatric trials, the most commonly reported AEs were headaches, upper respiratory infection symptoms, and diarrhea. A new toxicity reported in the pediatric trials that had not been seen in the previous adult trials was neutropenia (there were three events in the two pediatric trials all of which were grade 4). ${ }^{14,15}$

\section{Liver toxicity}

A dose-limiting toxicity of eltrombopag that was noted in clinical trials, which is not associated with romiplostim, was elevation of liver enzymes. It is recommended that transaminases 
should be monitored every 2 weeks during the dose adjustment phase and then monthly following the establishment of a stable dose because serum liver transaminase elevations have been reported and significant elevations may require that therapy should be stopped..$^{21}$ In pediatric randomized clinical trials, significant elevations (defined as $\geq 3$ upper limit of normal) of alanine aminotransferase were reported in 6\%-8\% of patients (vs $0 \%$ of placebo) and required discontinuation of drug in a total of seven patients. ${ }^{14,15}$

\section{Cataracts}

Ophthalmologic screening for cataract development is also recommended prior to initiation, and screening of patients for signs and symptoms of development of cataracts is recommended during therapy. In adult studies, treatment with daily eltrombopag was associated with the development of cataracts in some patients, but many of these patients were also treated with significant amounts of prior steroid therapy so that the true contribution of eltrombopag alone in this setting is still unclear. However, rodent toxicology studies did demonstrate cataract development suggesting that eltrombopag alone may contribute to this toxicity and monitoring is recommended. In pediatric studies, two of the 92 patients enrolled in PETIT2 were found to have developed new cataracts during the study duration. ${ }^{15}$

\section{Thrombosis/thromboembolism}

In adult trials with eltrombopag, there were both venous and arterial thrombotic events reported in patients, and these were observed even at low or normal platelet count. In the two reported pediatric clinical trials, there were no reported thrombotic complications. The study by Ramaswamy et al reported one episode of provoked deep venous thrombosis in a pediatric patient with an ankle fracture. ${ }^{18}$ A recent review of off-label use ofTPO RAs in pediatric patients with ITP prepared by the pediatric ITP Consortium of North America, a large collaborative of pediatric treating institutions across USA and Canada, noted two thrombotic events in 97 patients treated with TPO RAs and both of these events were in patients $(n=33)$ treated with eltrombopag and in patients with underlying risk factors for thrombosis. ${ }^{22}$ This suggests that the risk of thrombosis in patients being treated with eltrombopag may be increased in those patients with underlying risk factors and should be carefully weighed in susceptible patients.

\section{Summary}

Eltrombopag has recently been approved for use in children $>1$ year of age with chronic ITP with insufficient response to first line therapy. The available pediatric data suggest that this medication is effective at raising platelet count in many patients with ITP and is as effective in pediatric patients as it is in adults with chronic ITP. Patients should be monitored for the development of elevated serum transaminases and cataracts. Some patients, particularly those with underlying or acquired risk factors, may be at increased risk of thrombosis with therapy and a careful risk/benefit discussion should be held with families prior to initiation of therapy.

\section{Disclosure}

The author participated in clinical trials for GlaxoSmithKline plc and Astra Zeneca, Inc, consulted for Amgen, Inc and GlaxoSmithKline plc. The author reports no other conflicts of interest in this work.

\section{References}

1. McMillan R, Luiken GA, Levy R, Yelenosky R, Longmire RL. Antibody against megakaryocytes in idiopathic thrombocytopenic purpura. JAMA. 1978;239:2460-2462.

2. Cines DB, Cuker A, Semple JW. Pathogenesis of immune thrombocytopenia. Presse Med. 2014;43:e49-e59.

3. Ballem PJ, Segal GM, Stratton JR, Gernsheimer T, Adamson JW, Slichter SJ. Mechanisms of thrombocytopenia in chronic autoimmune thrombocytopenic purpura. Evidence of both impaired platelet production and increased platelet clearance. J Clin Invest. 1987;80:33-40.

4. Makar RS, Zhukov OS, Sahud MA, Kuter DJ. Thrombopoietin levels in patients with disorders of platelet production: diagnostic potential and utility in predicting response to TPO receptor agonists. Am J Hematol. 2013;88:1041-1044.

5. Neunert C, Lim W, Crowther M, et al; American Society of Hematology. The American Society of Hematology 2011 evidence-based practice guideline for immune thrombocytopenia. Blood. 2011;117:4190-4207.

6. Terrell DR, Beebe LA, Vesely SK, Neas BR, Segal JB, George JN. The incidence of immune thrombocytopenic purpura in children and adults: a critical review of published reports. Am J Hematol. 2010;85:174-180.

7. Neunert CE, Buchanan GR, Imbach P, et al; Intercontinental Cooperative ITP Study Group Registry II Participants. Bleeding manifestations and management of children with persistent and chronic immune thrombocytopenia: data from the Intercontinental Cooperative ITP Study Group (ICIS). Blood. 2013;121:4457-4462.

8. Wendling F, Maraskovsky E, Debili N, et al. cMpl ligand is a humoral regulator of megakaryocytopoiesis. Nature. 1994;369:571-574.

9. Kaushansky K, Lok S, Holly RD, et al. Promotion of megakaryocyte progenitor expansion and differentiation by the c-Mpl ligand thrombopoietin. Nature. 1994;369:568-571.

10. Li J, Yang C, Xia Y, et al. Thrombocytopenia caused by the development of antibodies to thrombopoietin. Blood. 2001;98:3241-3248.

11. Kuter DJ. The biology of thrombopoietin and thrombopoietin receptor agonists. Int J Hematol. 2013;98:10-23.

12. Williams DD, Peng B, Bailey CK, et al. Effects of food and antacids on the pharmacokinetics of eltrombopag in healthy adult subjects: two single-dose, open-label, randomized-sequence, crossover studies. Clin Ther. 2009;31:764-776.

13. Wire MB, Bruce J, Gauvin J, et al. A randomized, open-label, 5-period, balanced crossover study to evaluate the relative bioavailability of eltrombopag powder for oral suspension (PfOS) and tablet formulations and the effect of a high-calcium meal on eltrombopag pharmacokinetics when administered with or 2 hours before or after PfOS. Clin Ther. 2012;34:699-709. 
14. Bussel JB, de Miguel PG, Despotovic JM, et al. Eltrombopag for the treatment of children with persistent and chronic thrombocytopenia (PETIT): a randomised, multicentre, placebo-controlled study. Lancet Hematol. 2015;2:e315-e325.

15. Grainger JD, Locatelli F, Chotsampancharoen T, et al. Eltrombopag for children with chronic immune thrombocytopenia (PETIT2): a randomised, multicentre, placebo-controlled trial. Lancet. 2015;386:1649-1658.

16. Wang XL, Li AM. Successful use of eltrombopag in a child with refractory immune thrombocytopenia: case study and literature review. Blood Coagul Fibrinolysis. Epub 2015 Dec 8.

17. Mori M, Kato M, Koh K, Hanada R. Successful switching from eltrombopag to romiplostim in a pediatric patient with refractory chronic ITP. Rinsho Ketsueki. 2015;56:511-513.

18. Ramaswamy K, Hsieh L, Leven E, Thompson MV, Nugent D, Bussel JB. Thrombopoietic agents for the treatment of persistent and chronic immune thrombocytopenia in children. $J$ Pediatr. 2014; $165: 600 \mathrm{e}-605$ e.
19. Elalfy MS, Abdelmaksoud AA, Eltonbary KY. Romiplostim in children with chronic refractory ITP: randomized placebo controlled study. Ann Hematol. 2011;90:1341-1344.

20. Bussel JB, Buchanan GR, Nugent DJ, et al. A randomized, double-blind study of romiplostim to determine its safety and efficacy in children with immune thrombocytopenia. Blood. 2011;118:28-36.

21. US Food and Drug Administration [webpage on the Internet]. Highlights of Prescribing Information. Available from; http:/www.accessdata.fda. gov/drugsatfda_docs/label/2015/207027s0001bl.pdf. Accessed August, 2015.

22. Neunert C, Despotovic J, Haley K, et al. Thrombopoietin receptor agonist use in children: data from the pediatric ITP consortium of North America ICON2 Study. Pediatr Blood Cancer. In press.

\section{Publish your work in this journal}

Pediatric Health, Medicine and Therapeutics is an international, peerreviewed, open access journal publishing original research, reports, editorials, reviews and commentaries. All aspects of health maintenance preventative measures and disease treatment interventions are addressed within the journal. Practitioners from all disciplines are invited to submit their work as well as healthcare researchers and patient support groups. The manuscript management system is completely online and includes a very quick and fair peer-review system. Visit http://www.dovepress.com/ testimonials.php to read real quotes from published authors.

Submit your manuscript here: http://www.dovepress.com/pediatric-health-medicine-and-therapeutics-journal 